Dyah Pitaloka, Sudiarso, Setyono Yudo Triasmoro \& Cahyo Prayoga, 2021. PGPR, Pemupukan Anorganik Dan Vermikompost Terhadap Panjang Batang \& Diameter Tebu

(Saccharum officinarum L.) Di Screenhouse. Journal Viabel Pertanian. (2021), 15(2) 93-98

\title{
PGPR, PEMUPUKAN AN ORGANIK DAN VERMIKOMPOST TERHADAP \\ PANJANG BATANG \& DIAMETER TEBU (Saccharum officinarum L.) DI SCREENHOUSE
}

Diterima:

05 Agustus 2021

Revisi:

05 November 2021

Terbit:

23 November 2021

\author{
${ }^{1}$ Dyah Pitaloka, ${ }^{2}$ Sudiarso, ${ }^{3}$ Setyono Yudo Tyasmoro, \\ ${ }^{4}$ Cahyo Prayogo \\ ${ }^{1}$ Prodi Agroteknologi, Fakultas Sain dan Tehknologi, \\ Universitas Islam Raden Rahmat, \\ ${ }^{2,3,4}$ Department of Agriculture, Faculty of Agriculture, \\ Brawijaya University \\ ${ }_{1,2,3,4}$ Malang, Indonesia \\ E-mail: ${ }^{1}$ dyahpit88@yahoo.com, ${ }^{2}$ sudiarso1105@gmail.com \\ 3sytyasmoro@ub.ac.id, ${ }^{4}$ cahyoprayogo@yahoo.com
}

\begin{abstract}
ABSTRAK
Mengkombinasikan antara vermikompos, pupuk organik dan PGPR merupakam terobosan dalam pengembangan teknologi untuk meningkatkan produksi tanaman tebu. Penelitian ini bertujuan untuk mengetahui pengaruh kombinasi pupuk organic (kascing), anorganik dan PGPR terhadap pertumbuhan Panjang dan diameter tanaman tebu. Kegiatan dilakukan di screenhouse Universitas rawijaya Malang mulai bulan Agustus 2019 sampai Januari 2020. Perlakuan yaitu 1) PGPR 5 ml/liter dan $10 \mathrm{ml} /$ liter dikombinasikan dengan pupuk anorganik $100 \%(7 \mathrm{kw} \mathrm{ZA}+3 \mathrm{kw}$ KCL + 3 kw SP 36). PGPR $5 \mathrm{ml} /$ liter dan $10 \mathrm{ml} /$ liter dikombinasikan dengan vermikompos plus pupuk anorganik $50 \%$ dirancang dengan rancangan acak lengkap (RAL Faktorial) diulang 3 (kali), hasil menunjukkan bahwa pemberian PGPR 10 ml/liter terbukti mampu meingkatkan pertumbuhan tanaman tebu yaitu pada parameter diameter batang, panjang batang, kombinasi PGPR dan verokompos dicampur dengan pupuk anorganik $50 \%$ terbukti memperbesar diameter batang tanaman tebu.

Kata kunci : pertumbuhan vegetative tebu, PGPR, pupuk anorganik, pupuk vermikompos
\end{abstract}

\section{ABSTRACT}

Combine between fertilizer vermicompos, inorganic fertilizer and PGPR is a breakthrough in the development of agricultural technology to increase the growth of persistent vegetative state and the results of production plant cane. This researsh aims to determine the effect of a combination of organic fertilizers (vermicompost), inorganic and PGPR on the growth of the length and diameter of plant cane. Vegetative growth studycondukted in screenhouse Brawijaya university poor starts in August 2019 until january 2020. Treatment such as 1). PGPR $5 \mathrm{ml}$ per liter or 10 $\mathrm{ml}$ per liter combined with fertilizer inorganic $100 \%(7 \mathrm{kw} \mathrm{ZA}+3 \mathrm{kw} \mathrm{SP} 36+3 \mathrm{kw}$ kcl 2). PGPR $5 \mathrm{ml}$ per liter or $10 \mathrm{ml}$ per liter combined with vermikompos 10 ton/ha mixed with $50 \%$ inorganic fertilizer the research was compiled using random design comlplete factorial. Repeated three times result showing that the PGPR $10 \mathrm{ml}$ per liter proved to be able to increase long stalks of, the provision of a mixture of fertilizer and inorganic vermikompos $50 \%$ able to ancrease growth of plant in the trunk dameter, sugar cane, a combination pgpr and vermikompos mixed inorganic fertilizers able to enlarge the diameter of a plant stem sugar cane. 
Dyah Pitaloka, Sudiarso, Setyono Yudo Triasmoro \& Cahyo Prayoga, 2021. PGPR, Pemupukan Anorganik Dan Vermikompost Terhadap Panjang Batang \& Diameter Tebu

(Saccharum officinarum L.) Di Screenhouse. Journal Viabel Pertanian. (2021), 15(2) 93-98

Keywords : Vegetatif growth of sugarcane, PGPR, inorganik fertilizer, vermicompost organic fertilizer

\section{PENDAHULUAN}

Tebu merupakan tanaman rumut-rumputan penghasil gula (Miller ,et.al.,2006). Lubis (2015) mengemukakan, tebu adalah sumber pemanis utama di dunia hampir 70\% sumber pemanis berasal dari tebu. (Program swasembada gula nasional melaporkan bahwa kebutuhan gula Nasional pada tahun 2018 hanya menghasilkan gula 2,1 juta ton setiap tahunnya sementara kebutuhan tersebut mencapai 6,8 juta ton (Gusti, 2018). Kebutuhan gula di Indonesia merupakan kebutuhan pokok dimana konsumsinya mengalami peningkatan setiap tahun seiring dengan bertambahnya jumlah penduduk, namun, seiring dengan meningkatnya kebutuhan gula, Lahan pertanian di Jawa timur sebagian besar mengalami pergeseran penggunaan lahan dan degradasi akibat pemakaian pupuk anorganik dan pestisida yang berlebihan, hal ini menyebabkan penurunan kesuburan tanah, sehingga hampir semua lahan di Jawa timur tidak menunjang peningkatan produksi gula (Tarigan,et .al., 2006). Degradasi agroekosistem utamanya akibat pemakaian pupuk an organik berlebih menyebabkan tanah mengeras, fungsi mikroorganisme tanah menjadi terganggu, mengakibatkan menurunnya kualitas biologi tanah yang mempengaruhi kesuburan tanah. Penggunaan pestisida kimia yang berlebih dalam penanggulangan hama juga menjadi faktor pemicu degradasi lahan (Khairullah,2010). Hal yang harus diperhatikan pada budidaya tanaman tebu yaitu fase pertumbuhan vegetatif, karena fase vegetatif dapat mempengaruhi produksi tebu. Putra (2016) mengemukakan, pertumbuhan vegetatif yang baik sangat penting untuk mendapatkan produktivitas gula yang optimal dari tanaman tebu tersebut.

Untuk menangani kekurangan unsur hara dalam tanah yang telah terdegradasi sebagai upaya peningkatan hasil dan keuntungan dalam menanam tebu dapat dicapai melalui pemupukan dan pemanfaatan bakteri menguntungkan yang terdapat pada PGPR dan vermikompos (Saraswati,et.al., 2008); Sinha., et.al.,2010).

Mengombinasikan antara PGPR, pupuk anorganik dan pupuk organik vermikompos merupakan terobosan dalam pengembangan teknologi pertanian, karena salah satu upaya untuk meningkatkan hasil dibidang pertanian tidak terlepas dari kemajuan perkembangan teknologi dibidang pertanian. Syehfani (2000) mengemukakan, bahwa pemberian pupuk yang tepat, dan sesuai keutuhan tanaman merupakan hal penting dalam meningkatkan produktivitas pertanian.

Penelitian ini diharapkan dapat menemukan kombinasi pemaanfaatan bakteri dan pemupukan yang efektif dan efisien yang mampu meningkatkan Panjang batang dan memperbesar diameter batang.

\section{Metodologi}

Penelitian ini dilakukan di screnhouse Universitas Brawijaya Malang, pada bulan Agustus 2019 hingga bulan Januari 2020. Peralatan meliputi polybag, gembor, bak, jangka sorong, hand refraktometer, SPDA, LAF, penggaris kayu, kamera. Adapun bahan ialah PGPR, ZA, SP 36 dan KCL, vermikompost, bibit tebu CMG Malang Agribun. Penelitian ini dilakukan dengan RAL Faktorial , 2 (dua) faktor yaitu faktor PGPR (P) dan pupuk (V), terdiri dari tiga taraf yaitu P0 (tanpa PGPR), P1 (PGPR $5 \mathrm{ml}$ per liter), P2 (PGPR 10 $\mathrm{ml}$ per liter), V0 (Tanpa pupuk), V1 (pupuk anorganik 100\% $=5,26 \mathrm{~g} /$ polybag ZA ,2,63 g/polybag SP 36,2,63 g/polybag KCL) dan V2 (pupuk vermikompos $=400 \mathrm{~g} /$ polybag + pupuk anorganik 50\% = 2,63 g/polybag ZA,1,32 g/polybag SP 36,1,32 g/polybag KCL), sehingga terdapat kombinasi perlakuan yaitu $\mathrm{P}_{0} \mathrm{~V}_{0}, \mathrm{P}_{0} \mathrm{~V}_{1}, \mathrm{P}_{0} \mathrm{~V}_{2}, \mathrm{P}_{1} \mathrm{~V}_{0}, \mathrm{P}_{1} \mathrm{~V}_{1}, \mathrm{P}_{1} \mathrm{~V}_{2}, \mathrm{P}_{2} \mathrm{~V}_{0}$, 
Dyah Pitaloka, Sudiarso, Setyono Yudo Triasmoro \& Cahyo Prayoga, 2021. PGPR, Pemupukan

Anorganik Dan Vermikompost Terhadap Panjang Batang \& Diameter Tebu

(Saccharum officinarum L.) Di Screenhouse. Journal Viabel Pertanian. (2021), 15(2) 93-98

$\mathrm{P}_{2} \mathrm{~V}_{1}$ dan $\mathrm{P}_{2} \mathrm{~V}_{2}$. Masing-masing perlakuan terdapat 3 contoh tanaman dan diulang 3 kali sehingga jumlah total keseluruhan polybag adalah 81 ditambah 3 polybag tanaman cadangan.

\section{Pelaksanaan kegiatan penelitian meliputi :}

\section{Pengolahan lahan.}

Persiapan pengolahan media tanam dimulai dengan mengisi tanah kedalam polybag sebanyak $20 \mathrm{~kg} /$ poybag, media tanah diambil dari lokasi setempat, sebelum digunakan tanah dianalisa kandungan nutrisi dan mineralnya.

\section{Penanaman bibit tebu.}

Bibit tebu yang ditanam adalah bibit bud chip varietas CMG Agribun Malang umur 2,5 bulan, setiap satu polybag diisi 1 bibit bud chip.

\section{Pemberian PGPR dan pemupukan .}

PGPR diberikan dengan 2 cara yaitu dengan cara direndam selama 30 menit sesuai perlakuan dan menyiramkan larutan PGPR ke dalam polybag. Pemupukan di berikan dengan dua tahapan, tahapan pertama pemberian pupuk vermikompos diberikan saat olah tanah dengan memasukkan kedalam polybag yang sudah berisi tanah, tahap kedua pemberian pupuk anorganik diberikan saat tanaman tebu berumur 6 minggu setelah tanam dengan cara menletakkan pupuk anorganik ke dalam polybag dengan jarak $5 \mathrm{~cm}$ dari tanaman tebu.

\section{Pemeliharaan.}

Pemeliharaan meliputi penyiraman dengan intensitas penyiraman 3 kali seminggu, penyiangan gulma dilakukan setiap 2 minggu sekali dan perempesan daun negatif dilakukan setiap 2 minggu sekali

\section{Pengamatan.}

Pengamatan meliputi pengamatan non destruktif dilakukan dengan 6 kali pengamatan dengan jarak waktu 4 minggu sekali.

\section{Pengamatan nondestruktif meliputi :}

\section{a. Diameter barang}

Diameter batang diukur pada bagian tengan batang diamati pada umur tanaman 10 MST, 14 MST, 18 MST, 22 MST, 26 MST, 30 MST (Minggu Setelah Tanam)

\section{b. Panjang Batang}

Panjang batang diukur pada pangkal batang sampai dengan dibawah segitiga daun yang paling bawah serta diamati saat tanaman berumur 10 Minggu setelah Tanam (MST), 14 MST, 18 MST, 22 MST, 26 MST, 30 MST .

Pengujian Hipotesis dilakukan dengan analisis Dsaastat, jika menunjukkan pengaruh nyata maka dilanjutkan dengan uji BNT taraf 5\% . 
Dyah Pitaloka, Sudiarso, Setyono Yudo Triasmoro \& Cahyo Prayoga, 2021. PGPR, Pemupukan Anorganik Dan Vermikompost Terhadap Panjang Batang \& Diameter Tebu

(Saccharum officinarum L.) Di Screenhouse. Journal Viabel Pertanian. (2021), 15(2) 93-98

\section{HASIL DAN PEMBAHASAN}

\section{Diameter Batang}

Berdasarkan Sidik Ragam Anova bahwa terdapat interaksi nyata pada PGPR dan pemupukan (anorganik dicampur dengan vermikompos) dan menunjukkan pengaruh nyata pada parameter diameter batang tebu umur 22 MST, 26 MST dan 30 MST. Secara terpisah perlakuan tunggal perlakuan PGPR menunjukkan berpengaruh nyata pada umur 22 MST dan 30 MST, sementara pemberian pupuk (anorganik dicampur dengan vermikompos) juga menunjukkan pengaruh nyata terhadap parameter diameter batang tanaman tebu umur 22 MST, 26 MST dan 30 MST. begitu juga dengan sebagaimana tersaji di Tabel 1.

Tabel 1. Hasil rata-rata diameter batang tebu pada pertumbuhan vegetatif (satuan $\mathrm{cm}$ )

\begin{tabular}{ccccccc}
\hline \multirow{2}{*}{ Perlakuan } & \multicolumn{7}{c}{ Umur tanaman $10 \mathrm{sd} 30(\mathrm{MST})$} \\
\cline { 2 - 7 } & 10 & 14 & 18 & 22 & 26 & 30 \\
\hline P0V0 & 1,82 & 2,40 & 2,59 & $2,63 \mathrm{a}$ & $2,74 \mathrm{a}$ & $2,79 \mathrm{a}$ \\
P0V1 & 1,90 & 2,46 & 2,64 & $2,72 \mathrm{abc}$ & $2,78 \mathrm{ab}$ & $2,82 \mathrm{a}$ \\
P0V2 & 1,94 & 2,54 & 2,80 & $3,19 \mathrm{f}$ & $3,25 \mathrm{~d}$ & $3,30 \mathrm{~d}$ \\
P1V0 & 1,97 & 2,46 & 2,72 & $2,75 \mathrm{bcd}$ & $2,86 \mathrm{abc}$ & $2,97 \mathrm{ab}$ \\
P1V1 & 1,98 & 2,46 & 2,66 & $2,87 \mathrm{de}$ & $3,03 \mathrm{c}$ & $3,23 \mathrm{~cd}$ \\
P1V2 & 1,99 & 2,75 & 2,62 & $2,83 \mathrm{cde}$ & $2,94 \mathrm{bc}$ & $3,01 \mathrm{~b}$ \\
P2V0 & 2,00 & 2,46 & 2,71 & $2,89 \mathrm{e}$ & $3,03 \mathrm{c}$ & $3,10 \mathrm{bc}$ \\
P2V1 & 2,06 & 2,56 & 2,61 & $2,70 \mathrm{ab}$ & $2,94 \mathrm{bc}$ & $3,12 \mathrm{bcd}$ \\
P2V2 & 2,10 & 2,54 & 2,51 & $2,60 \mathrm{a}$ & $2,86 \mathrm{abc}$ & $3,09 \mathrm{bc}$ \\
\hline BNT 5\% & Tn & Tn & Tn & 0,12 & 0,19 & 0,18 \\
\hline
\end{tabular}

Keterangan : Angka dengan huruf abjad yang sama pada kolom sama, menunjukan tidak berbeda nyata pada Uji BNT 5\%, Tn (Tidak Nyata).

Data Uji BNT pada Tab. 1. Membeikan hasil bahwa pada perlakuan kombinasi PGPR dan kombinasi pupuk anorganik (kimia sintetis) dan vermikompos tidak menunjukkan berbedaan nyata pada umur 10, 14, serta 18 (MST) terhadap parameter diameter batang tanaman tebu, sedangkan pada umur 22, 26 dan 30 (MST) menunjukkan berbeda nyata. Umur 22 MST perlakuan P0V2 memperoleh nilai rerata tertinggi serta berbeda nyata dengan perlakuan yang lain. P2V0 tidak menunjukkan perbedaan dengan P1V2 dan P1V1. P1V2 serta P1V1 juga tidak berbeda dengan P1V0, P1V0 tidak berbeda nyata dengan P0V1, P2V1. Perlakuan P0V1, P2V1 tidak berbeda nyata dengan perlakuan P2V2 serta perlakuan P0V0.

Pertumbuhan tebu bisa ditandai dengan ukuran diameter batang, semakin besar ukuran diameter batang pertanda bahwa pertumbuhan tebu baik dan akan menghasilkan bobot tebu yang maksimal. Diameter batang tebu yang kecil menunjukkan pertumbuhan tebu yang kurang optimal. Penambahan unsur hara melalui pemupukan dan pemberian PGPR mampu memberikan pengaruh positip bagi pertumbuhan tanaman (Khamili., et.al,2009), karena pada PGPR terdapat zat pengatur tumbuh yang dapat merangsang pertumbuhan tanaman sehingga dimeter batang tebu semakin tumbuh besar. Wibowo (2018) menyampaikan bahwa batang mempengaruhi besarnya serapan nutrisi, semakin besar diameter batang akan semakin besar pula ukuran batang.

\section{Panjang Batang Tebu}

Hasil analisa sidik ragam anova pada panjang batang menunjukkan tidak terdapat interaksi pada perlakuan apikasi PGPR dan pupuk (anorganik dicampur dengan vermikompos). 
Dyah Pitaloka, Sudiarso, Setyono Yudo Triasmoro \& Cahyo Prayoga, 2021. PGPR, Pemupukan Anorganik Dan Vermikompost Terhadap Panjang Batang \& Diameter Tebu

(Saccharum officinarum L.) Di Screenhouse. Journal Viabel Pertanian. (2021), 15(2) 93-98

Secara terpisah perlakuan pemberian PGPR dan pupuk (anorganik dicampur dengan vermikompos) menunjukkan berpengaruh nyata terhadap parameter panjang tanaman tebu. Tabel 2 menyajikan rata-rata Panjang tebu pada umur tanaman 6 MST sampai dengan 26 MST (Minggu Setelah Tanam), berikut kami sajikan Tabel dimaksud.

Tabel 2. Hasil rata-rata Panjang Batang Tebu pada pertumbuhan vegetative $(\mathrm{cm})$

\begin{tabular}{lcccccc}
\hline Perlakuan & $6 \mathrm{MST}$ & $10 \mathrm{MST}$ & $14 \mathrm{MST}$ & $18 \mathrm{MST}$ & $22 \mathrm{MST}$ & $26 \mathrm{MST}$ \\
\hline $\mathrm{P}_{0}$ & $4,55 \mathrm{a}$ & $17,40 \mathrm{a}$ & 37,98 & $81,39 \mathrm{a}$ & $130,61 \mathrm{a}$ & 164,22 \\
$\mathrm{P}_{1}$ & $5,99 \mathrm{~b}$ & $20,11 \mathrm{~b}$ & 40,70 & $81,50 \mathrm{~b}$ & $144,78 \mathrm{~b}$ & 157,78 \\
$\mathrm{P}_{2}$ & $5,14 \mathrm{ab}$ & $16,24 \mathrm{ab}$ & 40,83 & $77,22 \mathrm{~b}$ & $131,39 \mathrm{a}$ & 160,94 \\
\hline BNT 5\% & 1,81 & 4,93 & Tn & 6,17 & 11,63 & Tn \\
\hline $\mathrm{V}_{0}$ & $4,69 \mathrm{a}$ & 17,04 & $33,84 \mathrm{a}$ & $79,00 \mathrm{a}$ & $131,00 \mathrm{a}$ & 163,06 \\
$\mathrm{~V}_{1}$ & $4,79 \mathrm{ab}$ & 18,64 & $41,61 \mathrm{~b}$ & $83,11 \mathrm{~b}$ & $141,00 \mathrm{~b}$ & 155,06 \\
$\mathrm{~V}_{2}$ & $6,21 \mathrm{a}$ & 18,07 & $44,06 \mathrm{~b}$ & $78,00 \mathrm{~b}$ & $134,78 \mathrm{a}$ & 164,50 \\
\hline BNT 5\% & 1,81 & Tn & 9,93 & 6,17 & 11,63 & Tn \\
\hline
\end{tabular}

Keterangan : Angka dengan huruf abjad sama pada kolom yang sama, menunjukkan tidak berbeda nyata pada Uji BNT 5\%. Tn (Tidak Nyata)

Hasil uji BNT pada Tabel 5 parameter panjang batang menyajikan bahwa pada umur 10 MST perlakuan P1 berbeda nyata dengan kontrol tetapi tidak berbeda nyata dengan P2, sementara perlakuan V1 tidak berbeda dengan perlakuan V0 dan V2 namun memperoleh nilai rata-rata tertinggi yaitu 4,79. Pada umur 10 MST P1 dan diperoleh nilai rata-rata tertinggi yaitu 20,11 namun tidak menunjukkan berbeda nyata dengan $\mathrm{P} 2$, sedangkan P2 tidak berbeda nyata dengan perlakuan P0. Sementara, V memperoleh hasil yang sama secara statistik, namun V1 memperoleh nilai rata-rata tertinggi dari perlakuan V0 dan V2. Umur 14 MST perlakuan P tidak berbeda nyata, sedangkan perlakuan V1 berbeda nyata dengan perlakuan V0, namun V1 tidak menunjukkan berbeda nyata dengan V2. Pada umur 18 MST P1 berbeda nyata dengan perlakuan P0 tapi tak berbeda dengan P2 , sementara perlakuan V1 berbeda nyata dengan V0 tapi tak berbeda nyata dengan V2. Umur 22 MST pada perlakuan P1 berbeda nyata dengan perlakuan P0 serta P2 dengan nilai rata-rata 144,78, dan perlakuan V1 berbeda dengan perlakuan V0 dan V2 dengan nilai ratarata 144,00. Pada umur 26 MST menunjukkan tidak berbeda nyata baik perlakuan $\mathrm{P}$ maupun V. Batang ialah bagian pada tanaman yang memiliki jaringan parenkim dengan sel yang aktif membelah (Miller, et.al, 2006). Pemanjangan batang merupakan indikasi dari pembelahan sel yang aktif pada sel yang ada pada batang. Untuk menunjang pembelahan sel yang aktif maka dibutuhkan unsur-nutrisi tersedia dan pengairan yang mendukung sehingga pertumbuhan batang tanaman menjadi lebih maksimal.

Sesuai dengan yang dilaporkan oleh James, (2004) bahwa Panjang Batang pada tanaman tebu dipengaruhi oleh kecukupan nutrisi, sehingga ukuran pupuk yang diberikan akan mempengaruhi panjang batang tebu. Panjang Batang tebu juga dipengaruhi pertumbuhan pada saat perkembangan vegetatif, yakni bertambahnya tinggi tanaman, seta bertambah panjangnya ruas batang, sehingga secara tidak langsung akan berkorelasi positip dengan panjang batang (Tarigan, 2006). Menurut Djajadi et al (2016) meningkatnya produksi tebu dipengaruhi oleh meningkatnya diameter batang dan meningkatnya Panjang batang tebu.

\section{KESIMPULAN DAN SARAN}

Berdasarkan penelitian tersebut di atas maka bisa disimpulkan sbb:

1. Pemberian PGPR $10 \mathrm{ml}$ per liter terbukti mampu meningkatkan panjang batang 
Dyah Pitaloka, Sudiarso, Setyono Yudo Triasmoro \& Cahyo Prayoga, 2021. PGPR, Pemupukan Anorganik Dan Vermikompost Terhadap Panjang Batang \& Diameter Tebu (Saccharum officinarum L.) Di Screenhouse. Journal Viabel Pertanian. (2021), 15(2) 93-98

2. Pemberian campuran pupuk anorganik dan vermikompos mampu meningkatkan pertumbuhan tanaman tebu yaitu pada diameter batang,

3. Kombinasi pupuk anorganik dan vermikompos dengan PGPR berpengaruh pada parameter diameter batang tanaman tebu.

Perlu dilakukan penelitian lanjutan pada tanaman tebu di lahan yang berbeda dengan perlakuan pemberian konsentrasi PGPR yang lebih banyak dan mungkin pupuk anorganik $100 \%$ dicampur vermikompos.

\section{DAFTAR PUSTAKA}

Djajadi, Hidayati S.N., Syaputra R., Supriyadi. 2016. Pengaruh Si Cair terhadap Produksi Rendemen Tebu. Jurnal Litri 22 (4), pp: 176-181.

Gusti. 2018. Gap areal dan produktivitas sebabkan produksi gula nasional rendah. Seminar Nasional yang bertajuk Kajian Komprehensif Pergulaan Menuju Ketahanan dan Kemandirian Industri Gula Nasional, Universitas Gajah Mada. Yogjakarta.

Grehensonhttps://ugm.ac.id/id/berita/16111.11 September 2018.

James, G. (2004). Sugarcane. BPC. Oxford OX4 2 Dq, United Kingdom. 216 Pp.

Khamili, K., \& G.N.A.S. Wirya. (2009). Pemanfaatan PGPR untuk Biostimulans dan Bioprotectants .Ecotropik 4 (2)). pp:131-135

Khairullah, Sutanto P., Firmansyah E., dan Harto D.. 2010. Pupuk Ghaly Organik. CV Rolies Lampung.

Lubis, M.M.R., Mawarni, L., Husni, Y. 2015. Respons Pertumbuhan Tebu (Saccharum offinarum L.) terhadap Pengolahan Tanah pada Dua Kondisi Drainase. J. Online Agroekoteknologi. Vol. 3., No. 1

Miller, R.A. Gilbert. (2006) Sugarcane Botany : A Brief View. Agronomy Dept, Florida Cooperative Extension Service, Institute of Food and Agricultural.

Putra, E., Sudirman, A., Indrawati, w. 2016. Pengaruh Pupuk Organik pada Pertumbuhan Vegetatif Tanaman Tebu (Saccharum officinarum L.) Varietas GMP 2 dan GMP 3. J. Agro Industri Perkebunan. Vol. 4., No. 2

Saraswati, R., dan Sumarsono. (2008). Pmanfaatan Mikroba Penyubur Tanah sebagai Komponen Teknologi Pertanian.Iptek Tanaman Pangan. 3 (1). pp: 41-58

Sinha, R. Agarwal, K. S Chauhan, K. Chandran, V Soni, B. K. (2010). Vermicultur Technology Reviving the Dreams of Sir Charles Darwin for Scientific Use of Earthworms in Sustainable Devellopment Programs. United Kingdom: Technology and Investment .pp :155 - 172.

Syekhfani. (2000). Arti Penting Bahan Organik bagi Kesuburan Tanah. Jurnal Penelitian Pupuk Organik.

Tarigan, B., \& Sinulingga. J. N., (2006). Laporan PKL di Pabrik Gula Sei Semayang PTPN II Sumatera Utara.

Wibowo, A. Z. (2018). Analisis Produksi Tebu menggunakan Pendekatan Fungsi Produksi. Frontir di PTPN X. Pangan. pp: 33-42. 